\title{
Care management and mental health
}

\author{
Graham Thornicroft, Paul Ward, Steve James
}

This is one of a series of articles looking at the forthcoming changes to community care

Box 1-Principles

of case

management

Continuity of care

Accessible services

Staff-patient

relationship

Titrating support to need

Facilitating

independence

Patient advocacy

Advocacy for services

\section{PRiSM (Psychiatric}

Research in Service

Measurement), Institute of Psychiatry, London

SE5 8AF

Graham Thornicroft, senior lecturer

South East London Commissioning Agency, London SE1 9RY Paul Ward, community and priority services contracts manager

London Borough of Southwark, London SE1 Steve James, community care coordinator

Correspondence to: Dr Thornicroft
The community care reforms will produce a new kind of key worker who will organise and budget for packages of care: the care manager. Care management goes live in April 1993 but is still poorly rehearsed and its performance may yet disappoint. This overview sets out the origins of case management, its transformation into care management, and the principles guiding its practice. To spell out how the concept works, plans for care management in Southwark's mental health services are described.

The roots of case management lie in social case work. Within the specialty of mental health the central coordinating function was first recognised formally in the United States by the Community Mental Health Centers Act (1963) and its 1975 amendments, which explicitly required the centres to link with other agencies providing care for long term patients. There has, however, been an increasing recognition in the United States over the past 25 years that community based services for people with long term mental illness have too often been fragmented. ${ }^{12}$ Thus, methods of drawing together the components of care were developed, especially in federally funded initiatives such as the Community Support Program. ${ }^{3}$

The principles most often ascribed to the concept of case management are outlined in box 1 . Continuity of care refers both cross sectionally, to a comprehensive range of services for people with long term mental illness, and longitudinally, to emphasise the need for enduring and possibly indefinite care for a substantial proportion of this group. ${ }^{4}$

In practice case management for people with long term mental illness has developed into a range of techniques that can be described along 12 different axes (box 2), ${ }^{5}$ which aim to ensure that patients with long term psychiatric disorders receive consistent and continuing services for as long as they are required ${ }^{6}$ and that services do not focus inappropriately on patients with less severe conditions.?

Case managers might give direct care to clients, in a model that emphasises the staff-patient relationship as the key component through which effective care is channelled, in the tradition of social case work. Brokerage models, however, give the case manager a

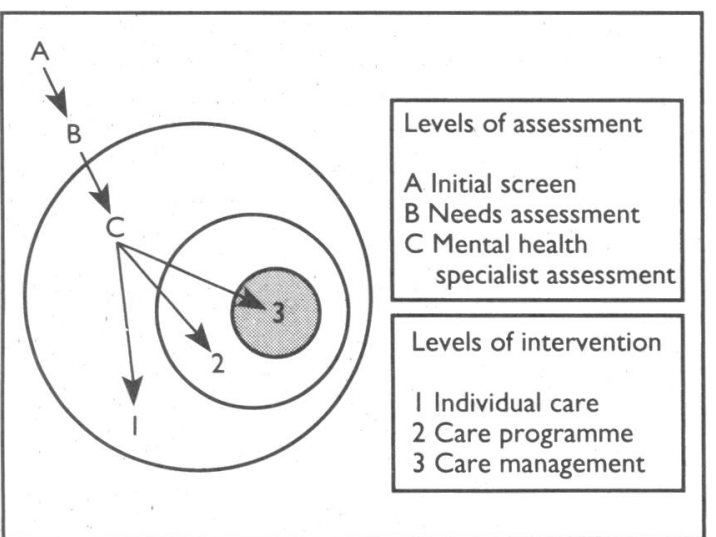

FIG 1-Levels of mental health assessment and treatment in care management system central and more distant coordinating function without any necessary direct contact with the patient. Whichever model is used, case management offers the same range of tasks to individuals. ${ }^{8-10}$ In Britain the concept of case management gained currency rapidly after 1985, when the House of Commons Social Services Committee's report on community care recommended that "the government give high priority to encouraging and monitoring the developing use of keyworkers." Sir Roy Griffiths took up the idea, under a different name, in 1988 in specifying that "no person should be discharged without a clear package of care devised and without being the responsibility of a named care worker." 12

\section{From case to care management}

The 1989 white paper on community care, Caring for People, took the implementation of these ideas further: "Where an individual's needs are complex or significant levels of resources are involved, the government sees considerable merit in nominating a 'case manager' to take responsibility for ensuring that the individual's needs are regularly reviewed, resources are managed effectively and that each service user has a single point of contact."13

The provisions of the 1990 National Health Service and Community Care $\mathrm{Act}^{14}$ make the following statutory requirements of case managers: "Where it appears to a local authority that any person for whom they may provide or arrange for the provision of community care services may be in need of any such services, the authority (a) shall carry out an assessment of his needs for those services and (b) having regard to the results of that assessment, shall then decide whether his needs call for the provision by them of any such services."

In 1991 case management was renamed "care management" in a guidance document from the Department of Health and Social Services Inspectorate, on the grounds that the term "case" was demeaning to the individual and misleading in that it is the care, and not the person, that is being managed. At the same time, however, central guidance made it clear that the version of care management now officially sanctioned was one in which direct service provision was not included, and that a brokerage model was therefore being endorsed. This important change marked the introduction of the purchaser/provider split in social services practice, with the care manager clearly identified as a purchaser but not as a provider of services.

\section{Implementing care management in Southwark}

In Southwark the processes of assessment and care management have been planned through an interagency group comprising local authority officers, and representatives from all the health providers and purchasers and the voluntary sector. The model of assessment which has been agreed has three levels (fig 1). Firstly, there is a screening stage, which can take place in many community settings-for example, at social services offices, general practitioners' surgeries, and centres of voluntary organisations, or in hospital before discharge. Information is recorded on 
Box 2-Twelve

axes to define case management in practice

\section{Individual/team} case management

2 Direct care/ brokerage

3 Intensity of interventions

4 Degree of budgetary control

5 Health/social service function

6 Status of case manager

7 Specialisation of case manager

8 Staff to patient ratio

9 Degree of patient participation

10 Site of contact

11 Level of intervention

12 Target population standard forms at screening and these are sent to the appropriate care management and assessment team, which is responsible for ensuring that each stage of the assessment and care management cycle is completed (box 3). Decisions on who needs assessment and who has priority will usually be made within the social services department, but in hospital such decisions can be made with health care staff.

The team member making the main assessment of needs for community care uses a structured form with headings covering all areas of potential need. Assessors can use an accompanying checklist to make a more detailed assessment of certain factors, allowing the resulting completed form to reflect more closely and personally the assessed person's needs. If a more detailed assessment is necessary evaluation by a specialist can be requested, to be completed within an agreed timescale. Throughout the process any informal carers should be consulted and should be offered their own assessments when appropriate. People being assessed are also offered an advocacy service in case they feel that they would benefit from additional support.

The model of care management planned for Southwark is mainly one of brokerage. In practice, however, social workers will still be able to offer personal help to their clients when this seems useful within the agreed care plan.

The local authority's obligation to provide services after assessment is a complex issue, with confusing messages coming from the Department of Health. Nevertheless, Southwark will provide services based on clear and publicly available eligibility criteria. Given the levels of need and the amounts of money transferred to Southwark for community care, there will probably be some unmet needs. Information on unmet needs will be collated to inform future allocation of resources.

\section{Assessing mental health in Southwark}

This model of assessment and care management will be used for all client groups in Southwark, but in the mental health services some additional features, both legislative and professional, will be incorporated into the overall structure.

Some mental health assessments are covered by separate legislation in the Mental Health Act 1983 and these will continue as at present. If such assessments result in admission to hospital the discharge policies under the NHS and Community Care Act 1990 will still apply.

\section{Box 3-Stages in care management and assessment}

Stage 1: Publishing information-Making public the needs for which assistance is offered and the arrangements and resources for meeting those needs.

Stage 2: Determining the level of assessment-Making an initial identification of need and matching the appropriate level of assessment to that need.

Stage 3: Assessing need-Understanding individual needs, relating them to agency policies and priorities, and agreeing the objectives for any intervention.

Stage 4: Care planning-Negotiating the most appropriate ways of achieving the objectives identified by the assessment of need and incorporating them into an individual care plan.

Stage 5: Implementing the care plan-Securing the necessary resources or services.

Stage 6: Monitoring - Supporting and controlling the delivery of the care plan on a continuing basis.

Stage 7: Reviewing - Reassessing needs and the service outcomes with a view to revising the care plan at specified intervals.
Services offered to people with mental health problems after discharge from hospital may have to take into account the care programme approach, ${ }^{15}$ the NHS and Community Care Act, and section 117 of the Mental Health Act. Southwark's model attempts to combine all the legislative requirements in one structure. It does this, for example, by defining three broad levels of service support (each with a corresponding type of service response): low (individual care), medium (care programme approach), and high (care management), where access to each of these is determined by the results of specialist mental health needs assessment.

Access to mental health services often bypasses social services departments (unlike services such as those for the elderly); thus the bulk of the initial screening will probably be undertaken by staff not working for the local authority. A high percentage of clients and patients will need complex interdisciplinary assessments. These specialist assessments may be performed by a variety of mental health professionals including social workers, psychiatrists, community psychiatric nurses, and psychologists. To make the process as uniform as possible the professionals will use standardised methods covering a range of possible problems, such as those included in the Camberwell assessment of need, which is being developed at the Institute of Psychiatry (box 4).

\begin{tabular}{|ll|}
\hline \multicolumn{2}{|l|}{ Box 4-Problem areas covered by } \\
the Camberwell assessment of need \\
Accommodation & Safety to self \\
Occupation & Safety to others \\
Specific psychotic & Money \\
problems & Childcare \\
Psychological distress & Physical health \\
Information about & Alcohol \\
condition and & Basic education \\
treatment & Company \\
Non-prescribed drugs & Telephone \\
Food and meals & Public transport \\
Household skills & Benefits \\
Self care and & \\
presentation & \\
\hline
\end{tabular}

\section{Discharge planning}

Adequate discharge planning will be a key factor in introducing successfully both care management and the accompanying changes in residential care funding. The past decade has seen an increasing amount of guidance from the departments of health and social security about the need for adequate discharge policies. This guidance has become increasingly prescriptive, to the extent that the most recent document strongly reinforces the view that no discharge from hospital should occur without a clearly agreed and implemented discharge plan in place for each patient.

This guidance has almost certainly improved substantially the extent and quality of discharge planning. In many cases, however, there are still important gaps between the services required and those available. This may improve as arrangements for care management are gradually introduced but for the foreseeable future plans will have to reflect a realistic view of available resources. This is particularly important if hospitals are to avoid becoming blocked with people awaiting the implementation of satisfactory discharge arrangements. When patients no longer need inpatient care but still have complex needs one of the key roles of care managers will be to facilitate rapid transfer home or to an alternative community setting. 


\section{Residential care}

One of the key motives behind the current legislative changes was to find a way of limiting expenditure on residential and nursing home care, which increased from $£ 10 \mathrm{~m}$ in 1979 to $£ 1$ billion in $1989 .{ }^{13}$ This increase was accompanied by a substantial rise in the provision of residential and nursing home places by the private and voluntary sectors. Given the projected growth in the number of elderly people likely to need support from health and social services, this increasing cost looked set to continue.

When legislative change was being considered, attention was often drawn to the so-called "perverse incentive" that saved local services money if they supported people in residential care rather than in their own homes. ${ }^{12} \mathrm{~A}$ clear intention of the changes was to enable care managers to buy domiciliary support, rather than residential care, where this was both more appropriate and inexpensive. Research in Southwark, however, has suggested that only about $15 \%$ of recent referrals to residential care were inappropriate.

In April responsibility for funding residential and nursing home care will be transferred from the Department of Social Security to local authority social services departments over a phased period of four years. Thus these funds immediately become cash limited. Doubts about the adequacy of the total transfer to social services departments have already been expressed, and it is becoming clear that there may well be insufficient resources for some client groups. This is most noticeable in the case of residential care services for drug and alcohol misusers, which have a high turnover of clients. In turn, this has raised concerns about the viability of such services, and what will happen if many projects have to close while still caring for people.

This will probably be one of the flash points as the new joint arrangements for assessment and care management become established. Two other potential problems loom large. Firstly, fundholding practices may find their obligation to buy community care services a disincentive from pressing for early discharge. Secondly, patients in hospital may also avoid hasty discharge to residential or care homes if they face means tested charges. Earlier and more thorough planning may be needed before discharge, and interagency troubleshooting arrangements may have to be set up should difficulties arise.

\section{Care management budgets}

The formula dictating how social security budgets are transferred to local authorities discriminates against Southwark and most other inner city authorities in London which have few existing private and voluntary providers within their boundaries. The formula rewards authorities with large numbers of local independent providers and does not allocate resources to the authorities from which residents using that independently run care originated. Thus Southwark, which exports $70 \%$ of adults needing residential care, will not receive adequate funding to pay for future placements. This is compounded by the relatively high level of psychiatric morbidity in areas such as Southwark and by a $11 \%$ reduction in NHS funding resulting from a new weighted capitation system, which is diverting money from inner south London to Kent and Sussex.

Guidelines from the Department of Health say that $85 \%$ of the social security element of the funding transfer should be spent on residental care for elderly people with a further $5 \%$ on their day care. Clearly, this leaves the other adult groups starved of resources for residential placements. Southwark, therefore, proposes spending less $-80 \%$ of the transferred monies on services for elderly people. Of the remaining $20 \%$ of

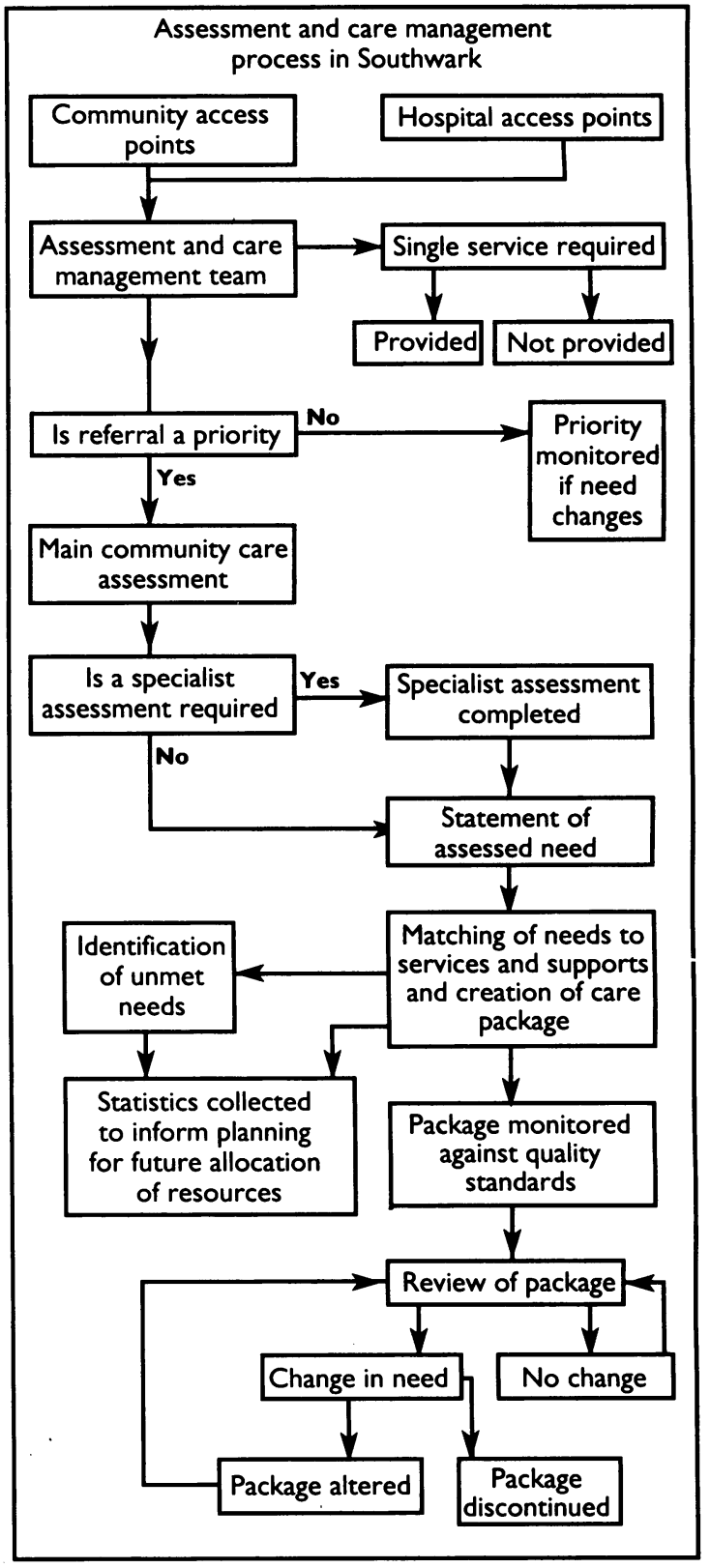

the total transfer people with mental health problems will receive approximately $6 \%$. This sum is inadequate and, even with rigorous prioritisation, will lead to some patients and clients having to be supported in the community when their needs could be met more adequately in residential care.

Southwark's model of care management will not devolve financial responsibility for community care to care managers. In the first year, budgets will be held by more senior staff and decision making on a day to day basis will be delegated to team managers. Very clear gatekeeping procedures and stringent setting of priorities will be needed to prevent overspending.

\section{Care management as a purchasing function}

Purchaser and provider divisions have been established in both health and social services authorities, but the splits occur at different levels. In social services departments purchasing work is oriented much more towards individuals than in the NHS, where it is oriented around services. This difference will not affect care management much in cases where social services teams are the main purchasers-for example, in services for people with learning disabilities. It is, however, much more important where the health 
authority is the main purchaser of community services -for example, in services for mental health, particularly in those for people with long term and severe mental illness and complex needs. For such patients decisions by care managers to commit resources will have to be integrated with the decisions about the deployment of health resources made by doctors, usually consultant community psychiatrists with specific responsibilities for discharge and aftercare under the Mental Health Act and care programme approach working in mental health multidisciplinary teams.

Mechanisms must be set up to ensure that commissioners in both health and social services receive feedback about needs assessment. This will be necessary if services in the NHS and those bought by care managers are to relate more closely to individual needs. This feedback will be particularly necessary in districts where care managers do not hold their own budgets.

\section{New perverse incentives}

The implementation of care management in April could rapidly illustrate how the admirable intentions of the government's community care policy might founder on the unintended consequences of more powerful forces and contradictions. Firstly, although the transfer of social security funds will allow more needs driven services, it will also cash limit expenditure. Secondly, this transfer punishes local authorities with few residential care homes and cuts off money for future expansion. Thirdly, the directive that care managers should not themselves give direct care runs counter to the core of good social work practice and creates a new corps of care administrators, thereby reducing the number of staff available to give direct care. Fourthly, no central guidance has emerged on how to coordinate at the local level, care management, ${ }^{1416}$ the care programme approach,,$^{1517}$ and hospital discharge procedures, thus inviting triplication of planning effort.

Fifthly, conflicting central guidance is emerging about the statutory requirements to provide services for people whose assessments show up unmet needs, or even to inform people about the results of assessment. ${ }^{18}$ Finally, the distinction between health and social care is proving much less clear in practice than in concept, and long running boundary disputes between agencies could erupt unless the problem is considered specifically in joint planning forums. Such joint planning is taking place now in Southwark.

\section{Managing care management carefully}

There is the ever present danger that insufficient overall funding will drown the potential benefit of the community care reforms. ${ }^{1920}$ And, for the current volleys of reforms to hit their targets, several extra initiatives will be required. When needs assessment information is fed into discussions on commissioning and planning it will probably highlight the need for district health authorities and local authorities (and, increasingly, general practitioner fundholders) to commission many community services jointly. Joint commissioning arrangements will allow specific gaps in service provision to be filled. Variations in joint commissioning practice between social services and health services will have to be piloted and monitored carefully.

Agencies will have to agree on definitions of needs and how people with different degrees of need will be prioritised when services are rationed. The division between health and social needs can be narrowed by joint training. Agreed procedures for appeals, complaints, and arbitration should be set up for users, and for authorities in dispute. Finally, models of care management must be tracked carefully and evaluated to show whether brokerage is the hub or the rub of community care.

We are pleased to acknowledge the helpful contributions of Matt Muijen and Peter Ryan of Research and Development for Psychiatry and of Geraldine Strathdee of the Maudsley Hospital in preparing this paper.

1 Braun P, Kochansky G, Shapiro R, Greenberg S, Gudeman JE, Johnson S, et al. Overview: deinstitutionalisation of psychiatric patients, a critical review of outcome studies. Am $\mathcal{I}$ Psychiatry 1981;138:736-74.

2 Kiesler C. Mental hospitals and alternative care. Am Psychol 1982;4:354-60.

2 Kiesler C. Mental hospitals and alternative care. Am Psychol 1982;4:354-60.
3 Tessler R, Goldman H. The chronic mentally ill: assessing the community support program. Cambridge, Massachusetts: Ballinger, 1982.

4 Anthony $W$, Cohen $M$, Farkas $M$, Cohen $B$. The chronically mentally ill and case management-more than a response to a dysfunctional system. Community Ment Health $f$ 1988;24:219-28.

5 Thomicroft $G$. The concept of case management for long-term mental illness. Int Rev Psychiatry 1991;3:125-32.

6 Torrey F. Continuous treatment teams in the care of the chronic mentally ill. Hospital Community Psychiatry 1986;37:1243-7.

7 Patmore C, Weaver T. Community mental health teams. Lessons for planners and managers. London: Good Practices in Mental Health, 1991.

8 Renshaw J, Hampson R, Thomason C, Darton R, Judge K, Knapp M. Care in the community: the first steps. Aldershot: Gower, 1988.

9 Intagliata J. Improving the quality of care for the chronic mentally disabled: the role of case management. Schizophrenia Bulletin 1982;8:655-74.

10 Challis D. Case management in community care. Aldershot: Gower, 1986.

11 House of Commons. Social Services Committee. Second report. Session 1984-85. Community care. London: HMSO, 1985:paragraph 181.

12 Griffiths R. Community care: an agenda for action. London: HMSO, 1988:v.

13 Secretaries of State for Health, Social Security, Wales, and Scotland. Caring for people. Community care in the next decade and beyond. London: HMSO, 1989:21. (Cm 849.)

14 House of Commons. The National Health Service and community care act. London: HMSO, 1990

15 Department of Health. The care programme approach for people with a mental illness referred to as the specialist psychiatric services 1990. London: Department of Health, 1990. (HC(90)23/LASSL(90)11.)

16 Onyett S. Case management in mental health. London: Chapman and Hall, 1992.

17 Department of Health, Social Services Inspectorate. Care management and assessment. Summary of practice guidance. London: HMSO, 1991.

18 Laming H. Implementing caring for people. Assessment. London: Department of Health, 1992.

19 British Medical Association. Priorities for community care. London: BMA, 1992 .

20 Blom-Cooper L, Murphy E. Mental health services and resources. Psychiarric Bulletin 1991;15:665-8.

\section{Correction}

\section{What proportion of congenital abnormalities can be} prevented?

Several authors' errors occurred in this paper by Andrew E Czeizel and others (20 February, pp 499-503). Firstly, in the second paragraph of the methods section common congenital abnormalities are defined as those with a frequency of $\geqslant 1 / 10000$; this should be $\geqslant 1 / 1000$. Secondly, in table I the entries for cleft palate and cleft lip with or without cleft palate are wrong: these lines should read:

749.0 Cleft palate

$\begin{array}{llllll}110 & 229 & 46 & 0.42 & 0.097 & 8.9\end{array}$

749.1-2 Cleft lip with

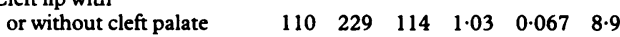

Finally, several of the references are incorrect. the references at the end of the first sentence of the fourth paragraph, and the first sentence of the sixth paragraph, of the methods section should be $3 a$, not 4 . The reference at the end of the first sentence of the ninth paragraph of the methods section should be $4 \mathrm{a}$, not 5 . The reference at the end of the third sentence of the first paragraph of the discussion should be 8 , not 10, and the next sentence should end with reference 9 . Finally, the references at the end of the second paragraph of the discussion should be 6 and 7 , not 8 and 9 .

The two new references are:

3a Czeizel A, Telegdi L, Tusnády G. Multiple congenital abnormalities. Budapest: Akadémiai Kiadó, 1988.

4a Czeizel A, Sankaranarayanan K. The load of genetic and partially genetic disorders in man. 1. Congenital anomalies: estimates of detriment in terms of years of life lost and years of impaired life. Mutat Res 1984;128:73-109. 